\title{
(2) Leadership for careful and kind care
}

\section{OPEN ACCESS}

'Department of Primary Care and Public Health, Imperial College London, London, UK

${ }^{2}$ The Patient Revolution, Rochester, Minnesota, USA ${ }^{3}$ School of Dentistry, The University of Mississippi Medical Center, Jackson, Mississippi, USA ${ }^{4}$ Division of Health Policy and Management, University of Minnesota System, Minneapolis, Minnesota, USA

${ }^{5}$ Knowledge and Evaluation Research Unit, Mayo Clinic

Rochester, Rochester,

Minnesota, USA

\section{Correspondence to} Dr Dominique Allwood, Department of Primary Care \& Public Health, Imperial College London, London, UK: dominique.allwood1@nhs.net

Received 25 February 2021 Accepted 26 May 2021

D Check for updates

(c) Author(s) (or their employer(s)) 2021. Re-use permitted under CC BY-NC. No commercial re-use. See rights and permissions. Published by BMJ.

To cite: Allwood D, Koka S, Armbruster $\mathrm{R}$, et al. BMJ Leader Published Online First: [please include Day Month Year]. doi:10.1136/ leader-2021-000451

Dominique Allwood, ${ }^{1,2}$ Sreenivas Koka, ${ }^{2,3}$ Ryan Armbruster, ${ }^{2,4}$ Victor Montori ${ }^{2,5}$

The fundamental role of healthcare organisations ought to be to care for patients. The care of patients is a human activity by which people with the capacity to care notice and respond well, with compassion and competence, to people who seek this care. ${ }^{1}$ This article describes how, instead, healthcare has industrialised care; with care degraded, care has become transactional. It has overwhelmed the capacity of both the people called to care and those that receive care, and has rendered care unsustainable. ${ }^{2}$ We propose that leaders can restore care by turning their organisations away from industrial healthcare and asserting their organisation's purpose to enact careful and kind care. This article describes that turning away and invites healthcare leaders to pioneer it from within their organisations. First, we explain the pathologies of care and an alternative to them, and then what leaders might do to turn this new strategy into action.

\section{THE INDUSTRIALISATION OF HEALTHCARE AND THE PATHOLOGIES OF CARE}

The public expects healthcare organisations to enable care by supporting the work of people responding to the problematic situations of their patients. Yet, healthcare organisations respond to their external environment and to the policies and structures-austerity, greed, poverty-that condition the kind of healthcare that clinicians give and patients receive. ${ }^{3}{ }^{4}$ Extrinsic motivators encoded in healthcare policies determine what is measured, ${ }^{5}$ how organisations are benchmarked and how organisations behave. ${ }^{6}$ Organisations have prioritised improving their financial position and sustainability, monitoring performance, characterising flow, stemming demand and counting beds and appointment slots. Increasingly often, the core purpose of healthcare, to care, has become side lined or postponed as organisations focus on prioritising operational and financial goals and pursuing reputation-burnishing targets.

In adapting to these determinants of industrial care, pathologies of care have emerged. These pathologies include hurry, blur, cruelty and burden (figure 1). As fewer resources are available to care, healthcare learns to process patients, clinical interactions become transactional, and processes focus on 'efficiency'. Patients receive hurried care as clinicians barely look up from notes or from the computer. ${ }^{7}$ Clinicians with limited time interrupt the patient and fail to notice the problematic human situation of this patient. ${ }^{8}$ Patients are seen as objects of care, ${ }^{9}$ but their situation remains nothing but a blur. Instead of cocreating a response specific to that patient's situation, ${ }^{10}$ clinicians offer recommended care for patients like this.
Care plans become complex and burdensome as they are assembled in uncoordinated fashion from all of the therapies recommended for patients with this and that diagnosis; this is particularly true for people with multiple chronic conditions. ${ }^{11}$ Waiting, and the delegation of boring and unimportant administrative and medical errands to patients and caregivers, add to the work of being a patient, wasting scarce time, energy and attention of patients and caregivers. ${ }^{12}$ Nearly $40 \%$ of patients living with ongoing chronic conditions, one of the largest and growing groups seeking healthcare, report feeling overwhelmed by the demands of healthcare. ${ }^{13}$ When overwhelmed, patients and caregivers implement care plans with poor fidelity which reduces healthcare effectiveness and wastes precious resources.

As patients are processed through the system, professionals working in healthcare in general, and clinicians (We use the term 'clinician' to refer to any health care professional-eg, nurse, physician, pharmacist, therapist-with the privilege of the bedside and there to care for patients) in particular, lose sight of their role, become unable to respond with compassion towards each patient, and eventually turn into depersonalised cogs in the wheel. ${ }^{14}$ They must comply with standards and meet targets, metrics and overcome documentation requirements. Fear of violating standard operating procedures and narrowing role specialisation prevent these professionals from responding to the particular needs of the people seeking their care. Due to these cruelties, nearly $40 \%$ of clinicians report symptoms of burnout, with many leaving patient care, and others, perhaps more disconcerting, continuing in care roles.

\section{AN ALTERNATIVE: CAREFUL AND KIND CARE}

There is an alternative to this unsustainable industrialisation of care. In our 2017 book, Why We Revolt, we called for a patient revolution, turning away from industrial healthcare towards careful and kind care. ${ }^{15}$ Here, the words careful-attentive concern, solicitude and error avoidance-and kind-exhibiting a gentle, sympathetic, or helpful nature relating to kindness and compasison ${ }^{16}$ acquire particular meaning when used to describe care. Careful care demands an evidence-based, safe and sensible response formulated to address the problematic situation of this patient not of patients like this. Careful care requires that clinicians see the whole patient, notice their problems in their biology and biography, and respond with compassion and competence by cocreating plans of care that make intellectual, emotional, and practical sense to each patient. Kind care involves humanity, recognising in each patient a member of the clinician's kin, a 


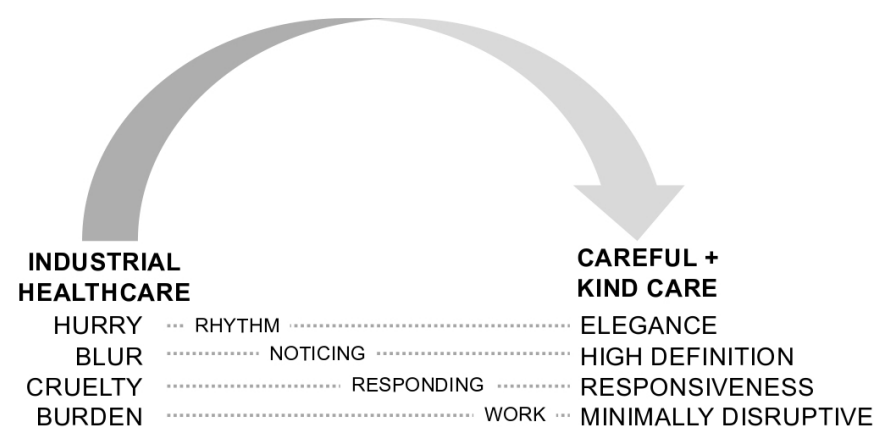

Figure 1 Industrial versus careful and kind care.

fellow human, one of $u s$ rather than one of them. Kind care recognises that patients have limited attention, time and energy, and that they should use their limited resources to fulfil their lives and loves rather than to complete the homework that healthcare assigns to them.

We propose that elements of careful and kind care include elegance, high definition, responsiveness and minimally disruptive care (figure 1). Hurry is not avoided simply by creating longer consultation time slots; these may waste the time of patient and clinician and reduce access to care. Hurried conversations may come across as highly efficient but are not; effective care has its own rhythm. Rather than efficient, healthcare must be elegant: there ought to be no waste and no haste. Elegance involves protecting the ability of patients and clinicians to set the tempo of their interaction, a tempo that encourages noticing what is the matter and responding in a way that reflects what matters. ${ }^{17}$ This does not always require more time, which would reduce access to care. Rather smarter scheduling, elimination of distractions, and presence and participation from clinicians and patients can promote that each visit takes place in the tempo of care. ${ }^{17}$

To respond well, clinicians must notice the patient's human need and problematic situation in high definition, in all its relevant biology and biography. This cannot be fully represented by test results and diagnostic labels in the medical record. This is particularly critical for patients living with multiple chronic conditions. For these patients, the biology of diseases and treatments interact with each other and with the stressors of living. To cope, they must weave care plans with the demands of their daily routines. While guidelines recommend care that is considered safe and effective, these recommendations should be a starting point for the cocreation of feasible and sensible care plans for and with this patient. ${ }^{18}$ Healthcare professionals must be empowered to recognise when to apply or break rules, policies, role descriptions, and standard operating procedures to be responsive to the problems of this patient. ${ }^{19}$ This responsiveness requires a culture fostering safety and integrity and a supportive emotional environment for healthcare professionals to be at their best. Ultimately, care must be minimally disruptive, that is, treatment must pursue the goals and priorities of the patient while minimising the demands it places on the patient's time, energy, and attention. ${ }^{2021}$

\section{A fundamental change: asserting that the core purpose of healthcare is to care}

Healthcare organisations align with the external environment, responding to its policies, urgencies, and incentives. Organisations are motivated by how they and their leaders are evaluated, and their performance rewarded (ie, rewarded for operational efficiency rather than to respond well to their patients' problems). Given these complexities, leaders may judge that acting in dissonance with these demands is neither possible nor sensible or too costly. Yet, healthcare organisations must play a pivotal role in leading change.

Leaders can choose to oppose, reinterpret and correct their organisation's alignment ${ }^{19}$ by fostering careful and kind care. Leaders have led pioneering transformations such as electronic health records, open notes, continuous quality improvement, lean, or value-based healthcare despite facing barriers to their adoption and long before there were policies and incentives for such initiatives. Their actions contributed to subsequent policy reforms. From these lessons, leaders can draw the necessary courage to shift their gaze away from industrial healthcare and embrace bold experiments to shift policy and change to the culture needed to achieve careful and kind care.

We turn our focus now to that urgent shift in gaze. We believe that leaders should assert that the sole purpose of their organisations is to care. This means that organisations must support the work of those who make care possible so that they can optimally notice each patient's problem and respond with compassion. Asserting this core purpose requires leaders to change both culture and strategy.

\section{Culture}

The organisational and leaders' language plays a central role in placing the care of the patient as the organisation's sole purpose. Language-the way the organisation expresses its culture through words, signs, symbols, and actions-both reflects and shapes the culture of the organisation. Preferring the language of care over the language of business will change how leaders and others in the organisation think and act. ${ }^{15}$ Too often, leadership speech that emphasises administrative and financial urgencies and promotes value to the organisation or to payers, can end up treating patients, clinicians, and staff as workers or commodities, and caring as merely throughput. ${ }^{22}$ Only people can care, and yet people easily disappear behind 'service lines' and 'population segments'.

When business language pervades the organisation, it manifests at the point of care where, jarringly, it is used to justify clinical actions as some care and some patients—-such as those judged to be 'high utilizers'-are considered wasteful, inefficient or low-value. Leaders should instead draw from the language of care. Although medicine and nursing have a long tradition of care, these disciplines have also evolved word habits that are uncaring, such as 'noncompliance', and objectify the patient, for example, 'the diabetic' or 'bed 24'. Care, however, has a long cultural tradition with its own language. Rather than push out business speak from the boardroom and the back office to the point of care, leaders should imbue their organisation with a language consistent with the organisation's purpose. They must draw words from the dictionary of care.

Stories written with the lexicon of care draw attention to the effect of policies on people and on their ability to care and vice versa. Stories can help uncover the efforts people must make to overcome organisational barriers to collaborate on behalf of a patient or to make meaningful human connections. Stories about existing pathologies of care and stories about the ability (or inability) of the organisation to foster careful and kind care can complement practice-based evidence. A core competency of caring and learning organisations is to tell these stories and learn from them, using them to drive improvements in care. ${ }^{123}$

\section{Mission and strategy}

Leaders judge clinical care on how clinicians and patients use resources, for the safety of their processes, and for their impact 
on organisational results, reputation and patient outcomes. Yet, when the primary aim is to care, an organisation should be judged by the extent it enacts and supports careful and kind care and its leaders should hold themselves accountable for achieving this result.

Because achieving careful and kind care demands collaboration and cocreation at all levels of the organisation, ${ }^{24}$ new forms of mutual accountability must be fostered at all levels. At the level of the organisation, leaders must focus their analyses primarily on the ability, at every level, of supporting, enabling and enacting careful and kind care. These analyses will draw from stories from the point of care and carefully selected metrics describing the care groups of patients have received. 'Is this the most careful and kind response we can muster?' and 'did we offer careful and kind care today?' are questions that clinicians and patients will ask leaders about their work, professionals will ask of each other at every level seeking to improve and innovate, and clinicians and patients will use to reflect together about their own joint achievements.

In industrial healthcare, leaders have become used to focusing on the organisation's reliability, effectiveness, safety, profit and efficiency. In recalibrating to careful and kind care, leaders must become champions of the 'other' domains of quality: patient centeredness, timeliness (with elegance), and equity. Accountability should also address 'the triple aim ${ }^{25} 26$ but reframed to emphasise patient and staff well-being, care experience (eg, tempo, burden of treatment, satisfaction with responsiveness of care by clinicians and patients), and resource use (eg, appropriateness of place of care (online or in person, at clinic or at home, synchronous or asynchronous, unhurried conversations, engagement of community assets)).

Aligning the organisation's strategy and policies and principles and practice to its purpose to care is an ongoing and multifaceted endeavour. For example, mutual accountability must start with sharing decision making equitably-with stakeholders in the administration and with 'patients as partners' who, together, define the outcome measures. Disseminated decision making requires a culture and systems that distribute autonomy, authority, and information. ${ }^{27}$ As the purpose, the 'why' of the organisation, turns away from industrial healthcare and towards careful and kind care, leaders must also use the organisation's evolving capabilities to innovate and improve their care processes. Industrial healthcare has developed these capabilities to address defects in reliability. ${ }^{28}$ Going further, these capabilities need deployment not just to improve organisational reliability but also to improve caring responsiveness. All this work and the resources needed to achieve it must reflect care as the purpose of the organisation, even as healthcare expands its mission to contribute to address the social determinants of health and improve population health. ${ }^{29}$

\section{TRANSLATING STRATEGY INTO ACTION}

Organisational leaders must develop and enable cultures, policies, practices, structures, processes, behaviours and motivators that make up the daily routines and operations at the level of teams and individuals to achieve care as the primary organisational purpose.

To enact these changes is no small feat and many leaders will understandably wonder where to start. We encourage leaders to identify examples of where they see the most industrial care and where they see careful and kind care already happening within their organisations. They can shine a light on these and in doing so encourage others to notice where these are occurring, draw learning from those, and identify opportunities for 'bold experiments' of change that affirm the purpose, advance the culture and realise the strategy of pursuing careful and kind care for all. Table 1 highlights areas that leaders could consider exploring in their endeavour.

Organisational leaders also have a role in cultivating interdependencies and systems thinking. Simply addressing each pathology of care as a 'defect' subject of a targeted quality improvement effort, risks exacerbating other pathologies. Without transformative change towards a culture of care, an improvement in one area may lead to failure in another. For example, addressing blur and improving the ability of clinicians to see the patient in high definition by completion of comprehensive questionnaires ahead of an outpatient visit could lead instead to a burdensome practice for clinicians as they spend time reviewing the questionnaire answers, to hurried visits as less time is allocated to explore the patient's situation in person since the task was delegated to the questionnaire, and to unresponsive care for patients since the true nature of the patient's situation may have been missed by the questionnaire. A significant portion of the documentation that interrupts care and burdens the clinician, for example, can be delegated to a scribe. Subsequent gains in efficiency afforded by the scribe could be translated into either an increase in the number of patients seen or an increase in the proportion of unhurried consultations. ${ }^{30}$ Therefore, innovation and improvement to address the interrelated pathologies of industrial healthcare will be less impactful without a concomitant shift in the organisational purpose towards care.

Leaders have to realise that the call for careful and kind care that we have emphasised for patient care also applies to the organisation's professionals and staff. Organisations cannot care, only people care. The transformation towards careful and kind care requires that organisations hire and retain people able, skilled and ready to care. Leaders can attract new healthcare professionals by fostering an organisation focused on care. This change in demand would signal to training entities what kind of professionals are needed, who should be admitted into training, and what kind of training they should receive. ${ }^{2}$ Powerfully, turning towards careful and kind care in practice will change the 'hidden curriculum', ${ }^{31}$ transmitting different language, values and norms that shape trainees' attitudes and behaviours. Healthcare professionals fully adapted to industrial healthcare will need to be nurtured into forms of working that kindle their compassion and elevate their care competence. Problems in their work must be noticed in high definition and responded with competence and compassion, cocreating improvements that make sense to those who will live and work with their consequences. And leaders must realise the humanity of each of the professionals who work in the organisation, that their lives are not all focused on healthcare, and that other joys may very well lie outside the workplace. Beyond mutual respect, organisations must enable mutual care. Caring for and about each other, mutual care across and between leaders and staff, will beget careful and kind care for patients.

\section{CONCLUSION-A CALL TO LEADERS}

Healthcare organisations must turn away from the efficient and sometimes cruel processing of patients according to standards of care for patients like them and towards cocreated, sensible, and minimally disruptive care for this patient. We suggest that leaders can pioneer a movement towards careful and kind care from within their organisations. 


\begin{tabular}{l} 
Table 1 Realising the strategy \\
\hline Pathologies of industrial care \\
Wurry might this currently look like? \\
Where the organisation evaluates efficiency as achieving more 'patient \\
care' in less time. \\
When brief and rushed encounters and poorly supported conversations \\
lead to lack of meaningful participation by the patient and the clinician. \\
When there is a focus on duration (rather than depth) of time with the \\
patient leading to rigid and unforgiving scheduling and an ethos of \\
'time is money'. \\
Where the organisation demands completion of extensive \\
documentation for auditing and accountability, structuring and \\
eventually displacing care itself. \\
Blur \\
Where care responds to symptoms or an abnormal test results in \\
isolation and with limited regard for the person that has them or their \\
situation. \\
Adhering to guidelines that produce standard practices for 'patients like \\
this' rather than respond to 'this patient'. The focus is on what should \\
be done rather than accounting for preferences, values and goals. \\
Data and decisions driven mainly by episodic, administrative and \\
aggregate data, or based on extreme or rare events (readmission, \\
death). The 'mundane and common' (inconveniences, suffering) remain \\
unmeasured and unattended.
\end{tabular}

Cruelty The organisation tells people 'what' to do through an extensive set of policies, protocols, and rules that fail to consider particular circumstance but instead seek conformity.

- The organisation accepts attrition and turnover of staff that suffer burnout, as a way of life. Where attempts are made to address this, they tend to be generic interventions to treat 'all staff' similarly, promote resilience at the level of individuals and focus on responding to issues rather than tackling the causation.

- When staff are fearful, discouraged, disempowered or disinterested in responding to a specific care situation that may deviate from general practices or policies leading to 'it's not my job, or I'm just doing my job'.
Alternative: careful and kind care
Elegance 
their potential contribution to enable and foster careful and kind care. As leaders translate strategy into action, it is important to align tactics, for example, how best to improve reliability in organisational processes while paying attention to the effect of these protocols on care; hiring of people with the ability to notice and response sensibly and with integrity; how to ensure better capabilities to notice and respond through policies of diversity and inclusion in hiring and developing staff; how to align incentives and recognitions with the organisation's core purpose. Examples of these tactics and case studies can bring additional clarity to the effort while enhancing the training of the next generation of leaders.

While a focus on care expands the relative importance of the different resources necessary for care, namely the intellectual and emotional availability of clinicians and time available to care, budgets play an oversized role as a determinant of industrial healthcare and as a potential barrier towards careful and kind care. Resources to sustain the organisation and advance its mission must be subject to careful stewardship.

We hope this article offers leaders the inspiration to undertake the journey towards achieving careful and kind care for all. Healthcare leaders, professionals and activists who use this article to take their first steps towards a culture of care are invited to share the lessons they learn from their experiments and contribute to a patient revolution.

\section{Twitter Dominique Allwood @DrDominiqueAllw}

Acknowledgements The ideas discussed in this paper emerged from discussions among the authors and with the Patient Revolution Fellows. We are grateful for their ideas as well as for the thoughtful critique and feedback on earlier drafts of Göran Henriks, Juan Pablo Brito, Bob Klaber, and Nish Manek. The authors take responsibility for the final draft, that represents their own views and not the views of their employers.

Contributors DA and VM conceived the idea for the paper and wrote the original draft. All four authors (DA, SK, RA, VM) were involved in drafting and editing the work and all give approval of the version published and agreement to be accountable for all aspects of the work. This work reflects the views of the individual authors and not their affiliated organisations.

Funding The authors have not declared a specific grant for this research from any funding agency in the public, commercial or not-for-profit sectors.

Competing interests None declared.

Patient consent for publication Not required.

Ethics approval Ethics Approval was not required. This manuscript does not report on original research findings therefore no ethical approval for research was sought.

Provenance and peer review Not commissioned; externally peer reviewed.

Author note Twitter: @vmontori @DrDominiqueAllw @patientrev

Open access This is an open access article distributed in accordance with the Creative Commons Attribution Non Commercial (CC BY-NC 4.0) license, which permits others to distribute, remix, adapt, build upon this work non-commercially, and license their derivative works on different terms, provided the original work is properly cited, appropriate credit is given, any changes made indicated, and the use is non-commercial. See: http://creativecommons.org/licenses/by-nc/4.0/.

\section{REFERENCES}

1 Montori VM, Hargraves I, McNellis RJ, et al. The care and learn model: a practice and research model for improving healthcare quality and outcomes. J Gen Intern Med 2019;34:154-8
2 Montori VM. Turning away from industrial health care toward careful and kind care. Acad Med 2019;94:768-70.

3 Owens J, Singh G, Cribb A. Austerity and professionalism: being a good healthcare professional in bad conditions. Health Care Anal 2019;27:157-70.

4 Mercer SW, Guthrie B, Furler J, et al. Multimorbidity and the inverse care law in primary care. BMJ 2012;344:e4152.

5 Kunneman M, Montori VM, Shah ND. Measurement with a wink. BMJ Qual Saf 2017;26:849-51.

6 Northcott D, Llewellyn S. Benchmarking in UK health: a gap between policy and practice? Benchmarking 2005;12:419-35.

7 Brown-Johnson C, Schwartz R, Maitra A, et al. What is clinician presence? A qualitative interview study comparing physician and non-physician insights about practices of human connection. BMJ Open 2019;9:e030831.

8 Singh Ospina N, Phillips KA, Rodriguez-Gutierrez R, et al. Eliciting the patient's Agenda- secondary analysis of recorded clinical encounters. J Gen Intern Med 2019;34:36-40.

9 Dowrick C, Heath I, Hiörleifsson S, et al. Recovering the self: a manifesto for primary care. Br J Gen Pract 2016;66:582-3.

10 Hargraves IG, Montori VM, Brito JP, et al. Purposeful SDM: a problem-based approach to caring for patients with shared decision making. Patient Educ Couns 2019;102:1786-92.

11 Tran V-T, Barnes C, Montori VM, et al. Taxonomy of the burden of treatment: a multicountry web-based qualitative study of patients with chronic conditions. BMC Med 2015;13:115.

12 May CR, Eton DT, Boehmer K, et al. Rethinking the patient: using burden of treatment theory to understand the changing dynamics of illness. BMC Health Serv Res 2014;14:281.

13 Tran V-T, Montori VM, Ravaud P. Is my patient Overwhelmed?: determining thresholds for acceptable burden of treatment using data from the compare e-Cohort. Mayo Clin Proc 2020;95:504-12.

14 West CP, Dyrbye LN, Shanafelt TD. Physician burnout: contributors, consequences and solutions. J Intern Med 2018;283:516-29.

15 Montori V. Why we Revolt: a patient revolution for careful and kind care. Rochester, MN, USA: Patient Revolution, 2017

16 Vogus TJ, McClelland LE. Actions, style and practices: how leaders ensure compassionate care delivery. BMJ Leader 2020;4:48-52.

17 Kebede S. Ask patients "What matters to you?" rather than "What's the matter?". BMJ 2016;354:i4045

18 Montori VM, Brito JP, Ting HH. Patient-centered and practical application of new high cholesterol guidelines to prevent cardiovascular disease. JAMA 2014;311:465-6.

19 Berwick DM, Loehrer S, Gunther-Murphy C. Breaking the rules for better care. JAMA 2017;317:2161-2

20 Mair FS, May CR. Thinking about the burden of treatment. BMJ 2014;349:96680.

21 May C, Montori VM, Mair FS. We need minimally disruptive medicine. BMJ 2009;339:b2803.

22 Groenewoud AS, Westert GP, Kremer JAM. Value based competition in health care's ethical drawbacks and the need for a values-driven approach. BMC Health Serv Res 2019:19:256.

23 Maddox TM, Albert NM, Borden WB, et al. The learning healthcare system and cardiovascular care: a scientific statement from the American heart association. Circulation 2017;135:e826-57.

24 Batalden M, Batalden P, Margolis P, et al. Coproduction of healthcare service. BMJ Qual Saf 2016:25:509-17.

25 Berwick DM, Nolan TW, Whittington J. The triple aim: care, health, and cost. Health Aff 2008:27:759-69.

26 Bodenheimer T, Sinsky C. From triple to quadruple aim: care of the patient requires care of the provider. Ann Fam Med 2014;12:573-6.

27 Laloux F. Reinventing organizations. A guide to creating organizations inspired by the next stage of human consciousness. Nelson Parker, 2014.

28 NHS Improvement. Building capacity and capability for improvement: embedding qualtiy improvement skills in NHS providers, 2017.

29 Maani N, Galea S. Physicians and social determinants of Health-Reply. JAMA 2020;324:1217.

30 Gottlieb M, Palter J, Westrick J, et al. Effect of medical Scribes on throughput, revenue, and patient and provider satisfaction: a systematic review and meta-analysis. Ann Emerg Med 2021;77:180-9.

31 Hafferty FW, Gaufberg EH, O'Donnell JF. The role of the hidden curriculum in "on doctoring" courses. AMA J Ethics 2015:17:130-9.

32 Marshall M, Cornwell J, Collins A, et al. Rethinking medicine. BMJ 2018;363:k4987. 